\title{
The history of the introduction of peppermint (Mentha $\times$ piperita L.) in Imperial Russia
}

\author{
Olga V. Shelepova ${ }^{1}$, Ekaterina V. Tkacheva ${ }^{2 *}$, and Elena V. Golosova ${ }^{3}$ \\ ${ }^{1}$ N. V. Tsitsin Main Botanical Garden of Russian Academy of Sciences, 127276 Moscow, Russia \\ ${ }^{2}$ Library for Natural Sciences of the Russian Academy of Sciences, 119991 Moscow, Russia \\ ${ }^{3}$ The Nikitsky Botanical Garden - National Scientific Center of the Russian Academy of Sciences, \\ Moscow branch, 119334 Moscow, Russia
}

\begin{abstract}
Peppermint (Mentha $\times$ piperita L.) has been and remains one of the most widely used herbs for medicinal purposes since its discovery. It is used in cosmetics, personal care products, food and pharmaceutical products both because of its taste and aromatic properties. In addition, mint is used for non-medical purposes, which makes its cultivation economically feasible. Information about the introduction of peppermint in Russia since the beginning of the XVIII century is scattered and / or incomplete. The purpose of this work is to provide an extensive descriptive overview of the introduction to the cultures of this species in imperial Russia (from the beginning of the XVIII century to the October Revolution). Archival and historical documents on the cultivation of medicinal herbs and the development of peppermint culture in Imperial Russia, virtual herbariums of the V.L. Komarov Botanical Institute of the Russian Academy of Sciences and the M.V. Lomonosov Moscow State University were studied.
\end{abstract}

\section{Introduction}

Representatives of the Mentha genus (Lamiaceae family) have long been used by mankind in folk medicine and cooking $[1,2]$. The first attempt at a botanical classification of the mint plant was undertaken by Pedanius Dioscorides (c. 40-90), a famous Greek physician and herbalist, whose teachings were considered classical from ancient times until the Renaissance [3]. The next classification of mint was carried out several centuries later by Karl Nilsson Linnaeus (1707-1778) in his work "Plant Species", published in 1753 [4]. In the 20-21 centuries, the classification of the genus was improved on the basis of genetic relationships between species [5]. However, it should be noted that in many medical treatises, various types of mint are referred to simply as mint, which makes it difficult, and often not possible, to accurately assess the use of each specific type. From the point of view of pharmacognosy, the therapeutic value of mint lies in the aerial parts of the plant, which can be dried and ground into powder or used fresh, as well as used to obtain essential oil [2]. The genus name Mentha was probably coined by the Greek philosopher Theophrastus (371-287 BC), who described several plant species from a botanical and agricultural point

\footnotetext{
*Corresponding author: gbsad_lib@mail.ru
} 
of view in his Study of Plants [2]. The name Mentha comes from classical Greek mythology, from Minte (Mente), a beautiful river nymph loved by the god of the underworld, Pluto. Different ancient texts describe different versions of this myth. The etymology of the word "mint" comes from the Old English minte (= mint plant), which comes from the Proto-Germanic language, through Latin - from the ancient Greek and is related to the Old Norse [2]. Currently, the genus includes 18 species, 31 subspecies or botanical varieties, and 11 recognized hybrid species [5, 6].

Among the whole variety of plants of this genus, Menthax piperita $\mathrm{L}$. is one of the most widely used plants in the world, which has long been safely used in medicines [7]. Although most peppermints have been known to mankind since ancient times, the first description of peppermint was made in 1696 by the English botanist John Ray (1627-1705) and published in the second edition of his Synopsis Methodica Stirpium Britannicarum [8]. The plants were found in garden mint crops in Burfordshire in England. There are two forms of peppermint - white and black, differing in morphological parameters and properties of the essential oil. Thus, the" white " peppermint essential oil has a more subtle and refined aroma, its yield is somewhat lower, it is less resistant to abiotic and biotic environmental factors [9]. Almost all the peppermint plant is applicable for medical purposes. The leaves and inflorescences are used as a remedy for colds, for various inflammatory processes and for disorders of the gastrointestinal tract. Decoctions and infusions from the aboveground part of the plant are used as an antimicrobial, antiviral and anti-inflammatory agent $[10,11]$. Among the secondary compounds in mint, a number of flavonoids are distinguished, which are highly effective antioxidants. It is known that these compounds slow down the oxidative degradation of lipids, improving the quality and nutritional value of food. In addition, peppermint is a source of a valuable product-an essential oil of great interest for the pharmaceutical, perfume and food industries [12].

Despite the fact that in the Russian-language both agricultural and scientific literature of the early XX century, it was often possible to find data that the culture of peppermint cultivation was developed in imperial Russia during the XIX and XIX centuries, most of the data on the history of the cultivation of peppermint in Russia is very sketchy and incomplete. The purpose of this work was to make an extensive overview of the introduction and development of the culture of growing peppermint in imperial Russia (from the beginning of the 18th century to the October Revolution).

\section{Materials and Methods}

The materials used are archival and historical documents on the cultivation of medicinal herbs and the development of M. piperita culture in Imperial Russia, virtual herbariums of the V.L. Komarov Botanical Institute of the Russian Academy of Sciences (BIN RAS) and the M.V. Lomonosov Moscow State University (MSU).

\section{Results and Discussion}

Medicinal plants in Russia were originally collected and bred in monasteries. So already in the XI century, the monks of the Kiev-Pechersk Monastery collected, grew and treated with herbs [13], for the purposeful cultivation of medicinal herbs, by order of Ivan the Terrible, an Apothecary's Chamber was opened in the XVI century [14], a "botanical garden with a pharmacy" was arranged in the Izmailovo residence of Tsar Alexey Mikhailovich [15]. By the XVII century, interest in medicinal plants in Russia stimulated the laying of pharmacy (medical) vegetable gardens and orchards, some of which have survived to this day, but their systematic development and laying began in Russia after the reforms of Peter the 
Great [16]. At the beginning of the XVIII century, at the field state pharmacies that supplied the Russian troops with medicinal raw materials, pharmacy warehouses and gardens began to appear, in which medicinal plants were collected, grown and stored. So, in 1714, an Apothecary's Garden was founded in St. Petersburg [17]. The main purpose of the Pharmacy Garden was the cultivation of medicinal plants, the collection and primary processing of raw materials, primarily for the needs of the army and navy. But from the first years of the existence of the pharmacy garden, scientific work was also carried out in it. Historically, the first scientific works were introduction tests of various plant species. In the catalog of seeds, published already in 1736, there were already 1275 species [18]. At the same time, the list of cultivated medicinal plants consisted of about 300 species, of which 6\% represented the domestic flora [19]. A total of 78 species of useful and medicinal plants were grown in the open ground, among which were representatives of the genus Mentha [20].

At about the same time, a state pharmacy was opened on the territory of the Poltava region in the city of Lubna, and in 1714 two pharmacy gardens were founded at it [21]. Here, according to T.P. Garmash and V.A. Zub [22], peppermint was grown since 1730, and by 1736 they even had installations for distilling essential oil. It is worth noting that we have not found reliable documentary evidence of this fact.

In the historical documents of the first half of the XVIII century, there is data on the harvesting of artificially grown mint. For example, in the Order of the Main Palace Chancellery there is a record of the consumption of flour and mint [23]. The term "cultural mint" is more pharmaceutical, as it indicates that this cultural plant has known chemical properties, thanks to which it is used by pharmacists. With a high degree of probability, in the first half of the XVIII century, the so - called German, garden or curly mint - M. crispa L. was mainly cultivated in Russia. (according to the modern classification - M. spicata L.). One of the confirmations of this assumption can be the herbarium of Abraham Ensa, one of the largest private collections of plants of the first half of the XVIII century, currently stored at the V.L. Komarov Botanical Institute of the Russian Academy of Sciences (BIN RAS) (LE) in St. Petersburg [24]. It is known that Abraham Ens was appointed a regimental doctor and served in Poltava and Lubny in 1747-1748. He had the opportunity to replenish his herbarium with samples of $M$. piperita. But among the 7 leaves of his herbarium with samples of the genus Mentha, there is only a sample of curly mintLE01084464 (Fig. 1).

Most likely, by the end of the XVIII century, $M$. piperita was already cultivated in Russia. Although the plant catalog compiled by P.S. Pallas of the first and one of the largest private botanical gardens in Russia at that time - the botanical garden of the Ural industrialist P.A. Demidov - does not contain peppermint among 7 types of cultivated mint [25]. The updated second catalog, published five years later, notes that the collection of cultivated mint has increased to 12 species, among them there are 5 species that are transferred to greenhouses for the winter. From this we can conclude that southern mint species were cultivated. Among the introduced mint species there, again, there is no peppermint [26]. However, already in the" List of pharmacy supplies", compiled in 1805 by Timofey Smelovsky, on behalf of the St. Petersburg Academy of Sciences, it is indicated that" Menthae piperitae seu piperiti dis herba and oleum " grows in large quantities in gardens [27]. In the first part of the "List", dedicated to plants growing in Russia intended for medical purposes, peppermint Menthae piperithae and the essential oil obtained from it already appear. In the second part of the "List of pharmacy supplies", which indicates plants grown in existing pharmacy gardens in Russia or collected in the fields, it is indicated that "Stipiteo (shoots) to collect Menthae piperitae in Lubny (up to $180 \mathrm{f}$.), Smolensk (up to 50 f.), St. Petersburg (up to 400 f.), Moscow (up to 200 f.). Total 830 pounds". 


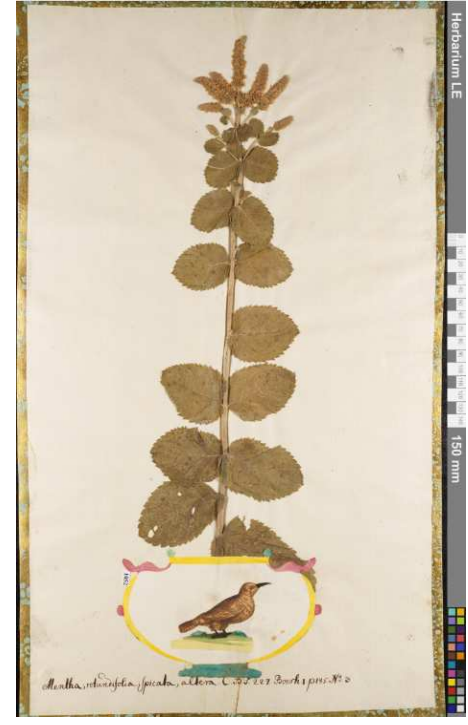

Fig. 1. A leaf from the herbarium of A. Ensa. Mentha, rotundifolia, spicata, altera. The place of collection and the time of collection-no data. Herbarium of BIN RAN (LE).

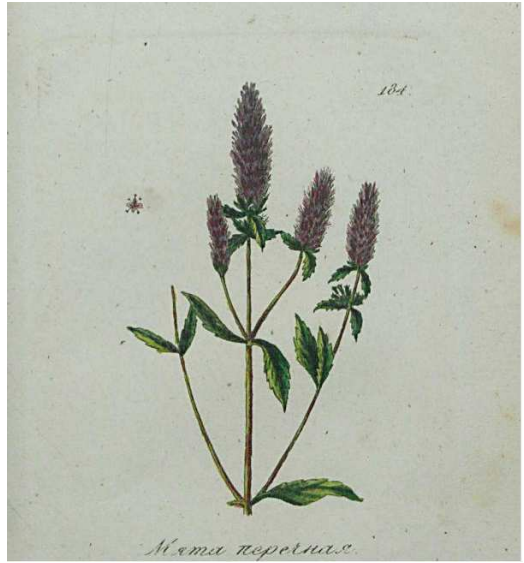

Fig. 2. Image 184 from the Russian medicinal herbalist, peppermint (M. piperita)

According to the archival data of the Poltava province, in 1805, by order of the GovernorGeneral Prince A. B. Kurakin, a pharmacy was founded in the Poltava province, which was headed by I. Sess from Moscow [28]. Already by 1806, there were two botanical gardens at the pharmacy, in which several types of mint were grown, including peppermint. In the Russian medicinal herbalist [29], a description and drawing of peppermint is given (Fig. 2), it is indicated that it is better than curly mint, it is described for what diseases it can be used, and a separate description of the use of leaves, mint water and essential oil is given.

The highest interest in the cultivation of peppermint was formed during the XIX century. Mainly black Mitchamic mint was grown, but white Mitchamic mint was also found [30]. Mint was grown in many provinces of the central part of Russia (Yaroslavl, Tula, Voronezh, Tambov, Kazan, Saratov), in the south and south-west of Russia (Poltava. Kharkiv, Taurida, Kiev and Podolsk) and in the Polish provinces near Warsaw [31].

At the same time, not so much attention was paid to botanical studies of cultivated peppermint. This is due to the fact that botanists paid less attention to cultivated plants. Thus, in the "Flora of Russia" published in 1847-1849 by S. F. Ledebour [32], peppermint is not listed among the entire variety of mint species growing on the territory of Russia. It is noted only in the Botanical Dictionary compiled by N. Annenkov for "botanists, rural owners, gardeners, foresters, pharmacists, doctors, travelers to Russia and rural residents in general". It describes the species, growing conditions and pharmaceutical properties [33]. There are also practically no cultivated mints in herbariums of that time. For a researcher to find herbarium sheets with cultivated plants is more a happy accident than a pattern. Here is how a major specialist in medicinal plants, F. A. Saciperov, wrote about it in 1913 [34]: "For example, there was not a single cultural form of mint in the Russian Herbarium of the Imperial Botanical Garden of Peter the Great. In the general Herbarium, you can find only two samples of cultural mint plant from Outside Russia." In the herbarium of the M.V. Lomonosov Moscow State University there are sheets with collections of peppermint, but as F. Saciperov noted, only some labels indicate the places of collection of plants (Fig. 3) [35]. 


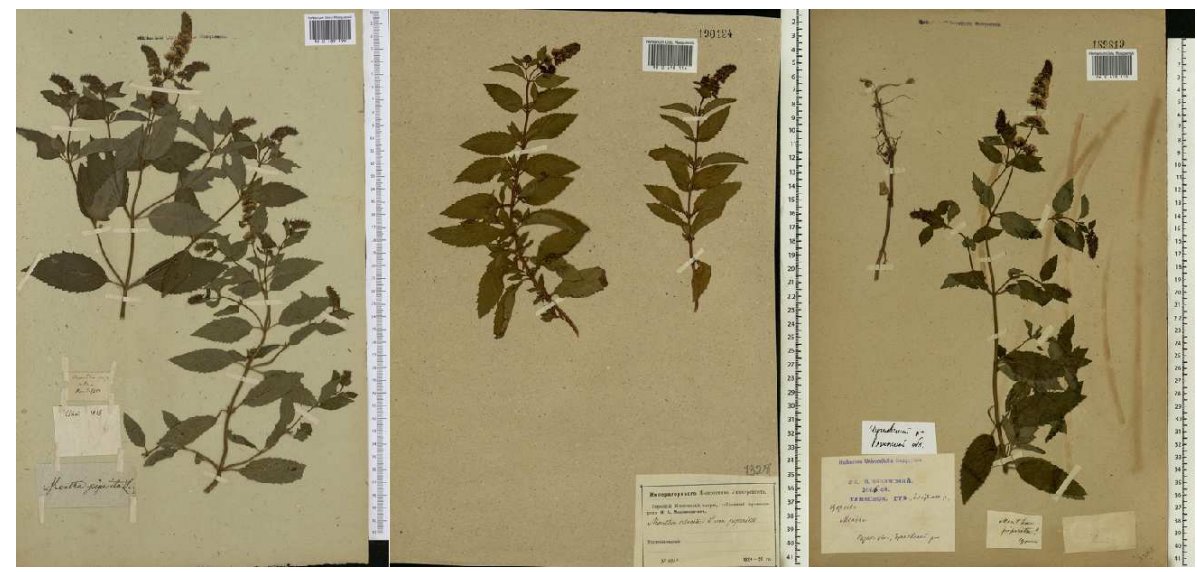

Fig. 3. Leaves from the herbarium of M. piperita-MW0789499, MW0498116 and MW0498110. The place of collection is indicated at the sample MW0498110-Tambov Province, Elatomsky district, Tserlyovo. Herbarium of Moscow State University (MW).

According to the definition of specialists of the late XIX-early XX centuries, the following forms were attributed to peppermint: Mentha piperita L. var. typica; Mentha piperita L. var. glabrata Vahl.; Mentha piperita L. var. Langii Stedel. [34].

It was at this time that the study of individual mint plant races growing in Russia was being established, and work on mint breeding began. One of the first varieties of peppermint was bred by Professor of the Imperial Kharkiv University A. E. Zaikevich [36]. By the beginning of the First World War, industrial production of peppermint was established in the Russian Empire. And at the same time, within the framework of the "Program for the study of cultivated and Wild plants", scientific support for the cultivation of peppermint began. It provided for carrying out anatomical, morphological, physiological, agrotechnical, phytochemical and even genetic-breeding studies [37].Thus, it can be stated that the introduction of peppermint in the Russian Empire began in the late XVIII-early XIX century. And by the beginning of the XX century, peppermint was grown on an industrial scale, both for pharmaceutical purposes and for the production of essential oil. The first scientific botanical studies of the species $M$. piperita were started at the beginning of the XX century.

Acknowledgement. The reported study was carried out in accordance with the MBG RAS Research Project No 118021490111-5, the Library for Natural Sciences of RAS Research Project No 075-00649-21-00 and with the NBS-NSC RAS Research Project No 110829-2019-0032.

\section{References}

1. F. Naghibi, M. Mosaddegh, M. M. Mohammadi, A. Ghorbani, A., Iranian J. Pharm. Res., 4 (2010)

2. F. Anwar, A. Abbas, T. Mehmood, A.-H. Gilani, N. Rehman, Phytotherapy Research, 33 (2019)

3. H.A. Silva, Biology, 9(12) (2020)

4. C. Linnaeus, Species plantarum (Ray Society, London, 1764)

5. GBIF, Global Biodiversity Information Facility. Available at: https://www.gbif.org/what-is-gbif (Accessed June 28, 2021).

6. A. O. Tucker, R. F. C. Naczi, In Mint: The Genus Mentha; Lawrence, (Taylor \& Francis Group, Boca Raton, FL, USA, 2007) 
7. S. C. C. Trevisan, A. P. P. Menezes, S. M. Barbalh, E. 1. Guiguer, World J Pharm Med., 3(1) (2017)

8. A. J. Ray, Synopsis methodica stirpium Britannicarum: in qua tum notae generum characteristicae traduntur, tum species singulae breviter describuntur: ducentae quinquaginta plus minus novae species partim suis locis inseruntur, partim in appendice seorsim exhibentur: cum indice \& virium epitome (Prostant apud Sam. Smith ad insignia principis in coemeterio D. Pauli, Londini, 1696)

9. S. Foster, American Botanical Council - Botanical Series, 306 (1996)

10. E. Herro, J. E. Sharon, Dermatitis, 21(6) (2010)

11. A. Balakrishnan, J. Pharm. Sci. \& Res., 7(7) (2015)

12. B. Nair, International Journal of Toxicology, 20(3) (2001)

13. L. A. Olshevskaja, Dictionary of Scribes and Scribes of Ancient Russia (Nauka, Leningrad, 1987)

14. V. Inohodcev, Chemistry \& Life, 1 (1981)

15. I. E. Zabelin, History of Russian life since ancient times (Eksmo, Moscow, 2020)

16. V. A. Kulikov, Vestnik Pharmacii, 58(4) (2012)

17. D. V. Geltman, Studies in the History of Biology, 6(3) (2014)

18. J. G. G. Siegesbeck, Primitae florae Petropolitanae sive catalogus plantarum tam indigenarum quam exoticarum, quibus instructus fuit Hortus Medicus Petriburgensis per annum MDCCXXXVI, (Samuel. Laur. Frölich, Rigae, 1736)

19. I. A. Pautova, Introduction of Species of the family Lamiaceae (the example of the collection of useful plants of the Botanical Garden of Peter the Great BIN RAS), Proceedings of the XIV Congress of the Russian Botanical Society and the conference "Botany in the Modern World", 18-23 June, Mahachkala (2018)

20. I. A. Pautova, Worksof the State Nikit. Botan. Gard., 146 (2018)

21. V. N. Samorodov, S. V. Pospelov, Turning the pages of the century-old history of the experimental station of medicinal plants in Proceedings of Fifth International Scientific and Practical Internet Conference, 2016, Poltava, Ukraine (2016)

22. T. P. Garmash, Bull. Soc. Nat. Moscou, 120(2) (2015)

23. I. A. Dashkov, Order of the Chief Palace Chancellery on the recording of the consumption of flour and mint (1743)

24. A. K. Sytin, D. D. Slastunov, The Herbalism of Abraham Enns (Lubavitch, St.Petersburg, 2020)

25. P. S. Pallas, Catalog of the plants in the garden of His Excellency Prokopiy Akinfievich Demidov, a real State Councilor and a famous benefactor of the Imperial House of Education in Moscow (Typography of the Imperial Academy of Sciences, St.-Petersburg, 1781)

26. P. S. Pallas, Catalog of plants according to the alphabet collected from the four parts of the world; with an indication of the botanical characters; found in the garden of the Actual State Councilor Prokofy Demidov (F. Gippius, Moscow, 1786)

27. T. A. Smelovskii, Inventory of apothecary supplies, compiled by order of the St. Petersburg Academy of Sciences in 1805 by academicians (1805)

28. I. F. Pavlovskii, Botanical gardens in Poltava, cultivation and collection of medicinal plants in Poltava province in the last century in Proceedings of the Poltava Scientific Archives Commission, Poltava, Ukraine (1915) 
29. G. I. Kashinskii, Russian medicinal herbalist: containing descriptions of domestic medicinal plants, with their qualities replacing foreign ones (Military Printing House, St.-Petersburg, 1817)

30. Peppermint, its cultivation and extraction of peppermint oil (Immer \& Son Trading House, Moscow, 1894)

31. I. Us. Palimpsestov, Agricultural Society of Southern Russia, 4 (1855)

32. C. F. Ledebour, Flora Rossica (Stuttgartiae, 1847-1849)

33. N. Annenkov, Botanical Dictionary (Typography of the Imperial Academy of Sciences, St.-Petersburg, 1878)

34. F. Saciperov, Proceedings of the Bureau of Applied Botany, 7 (1913)

35. Moscow Digital Herbarium: Electronic resource. Moscow State University, Moscow. Available at: https://plant.depo.msu.ru/ (Accessed 22.06.2021)

36. N. A. Lvov, S. V. Yakovleva, Research and breeding of peppermint (Lubni, 1931)

37. N. N. Monteverde, Development and current status of the collection and culture of medicinal plants in Poltava province (St.-Petersburg, 1916) 